\title{
Exopolysaccharide from Paecilomyces lilacinus modulates macrophage activities through the TLR4/NF-кB/MAPK pathway
}

\author{
CHAO HE $^{1 *}$, HAI-YAN LIN ${ }^{1 *}$, CAI-CHUN WANG ${ }^{1,2^{*}}$, MING ZHANG $^{1}$, YING-YING LIN $^{1}$, \\ FENG-YING HUANG ${ }^{1}$, YING-ZI LIN ${ }^{1,3}$ and GUANG-HONG TAN ${ }^{1}$ \\ ${ }^{1}$ Hainan Provincial Key Laboratory of Tropical Medicine, Hainan Medical College, Haikou, Hainan 571199; \\ ${ }^{2}$ Department of Respiratory Medicine, The First Affiliated Hospital of Hainan Medical College, Haikou, Hainan 570103; \\ ${ }^{3}$ Department of Immunology, Hainan Medical College, Haikou, Hainan 571199, P.R. China
}

Received January 26, 2019; Accepted September 26, 2019

DOI: $10.3892 / \mathrm{mmr} .2019 .10746$

\begin{abstract}
Multiple exopolysaccharides (EPSs) have been isolated from various organisms in extreme environments and have yielded a variety of activities. The present study evaluated the immunomodulatory capabilities of an EPS (termed PH-EPS) derived from the fungus Paecilomyces lilacinus PH0016, which was isolated from a tropical and hyperhaline environment in southern China. The macrophage RAW 264.7 cell line was used to investigate the mechanism of PH-EPS-induced macrophage activation. The results indicated that RAW 264.7 macrophages were activated by PH-EPS, in an effect slightly inferior to lipopolysaccharide (LPS), as evidenced by secretion of interleukin (IL)-1 $\beta$, tumor necrosis factor (TNF)- $\alpha$ and nitric oxide (NO), and by significantly increased phagocytosis in the cells treated with PH-EPS. Nuclear factor (NF)- $\kappa B$ p65 was significantly translocated into the nucleus in the PH-EPS-treated cells. In addition, expression of inducible NO synthase (iNOS) and I $\mathrm{kB}-\alpha$ degradation were enhanced in PH-EPS-treated cells. The phosphorylation levels of p38, JNK and ERK were also significantly increased in the PH-EPS-treated cells. Furthermore, IL- $1 \beta$ and TNF- $\alpha$ production was markedly decreased in PH-EPS-treated cells when the mitogen-activated protein kinase (MAPK) pathways were blocked by the inhibitor Dectin-1 and by antibodies against Toll-like receptor 4 (TLR4). The present results indicated that PH-EPS from Paecilomyces lilacinus possessed the capability
\end{abstract}

Correspondence to: Professor Guang-Hong Tan, Hainan Provincial Key Laboratory of Tropical Medicine, Hainan Medical College, 3 Xueyuan Street, Haikou, Hainan 571199, P.R. China E-mail: tanhoho@163.com

Professor Ying-Zi Lin, Department of Immunology, Hainan Medical College, 3 Xueyuan Street, Haikou, Hainan 571199, P.R. China

E-mail: 13198997808@126.com

*Contributed equally

Key words: exopolysaccharide, mitogen-activated protein kinases, nuclear factor- $\kappa \mathrm{B}$, Paecilomyces lilacinus, Toll-like receptors of activating RAW 264.7 cells via the TLR4/NF-кB/MAPKs signaling pathway.

\section{Introduction}

Macrophages exist in all vertebrate tissues and are important in the immune system, where they may connect innate and adaptive immunity (1-3). Macrophages are involved in activating many innate and adaptive immune responses, including the production of various soluble mediators, the phagocytosis of apoptotic cells and even the presentation of non-self antigens with their own human leukocyte antigen molecules to T lymphocytes for initiating adaptive immunity (4). Although most of the functions in macrophages are constitutive, fully competent activation of macrophages still requires external stimulation, such as contact with cytokines, cooperation with certain extracellular matrix components and interaction with $\mathrm{T}$ cells (4). Therefore, macrophages are considered to be the major target cells of various biologically active substances. Macrophages can be activated through various signaling pathways. At present, the most studied signaling pathways related to macrophage activation are the mitogen-activated protein kinase (MAPK) and nuclear factor (NF)- $\mathrm{B}$ pathways (5-10). Various pattern recognition receptors (PRRs) exist on the macrophage surface, such as complement receptor type 3 (CR3), Dectin-1 and Toll-like receptors (TLRs) (11-14). In addition, various stimuli can act as ligands that bind to these receptors and then prime the signaling pathways to activate macrophages (12-14).

At present, an increasing number of exopolysaccharides (EPSs) have been isolated from special natural sources, including bacteria, fungi and plants. Multiple studies have shown that EPSs have antioxidant, immunomodulatory, antiviral, antibacterial, antitumor and even antidiabetic effects (15-18). Therefore, EPSs may serve as immune modulators in a variety of applications.

Recently, our group discovered a novel fungus strain of Paecilomyces lilacinus, PH0016, which was isolated from a mangrove environment in Hainan, a tropical and hyperhaline subenvironment in southern China (19-21). To date, only one study has reported the host-parasite interactions between P. lilacinus and macrophages (22). To the best of our 
knowledge, there are no studies related to EPSs derived from P. lilacinus. The present study isolated the EPS from PH0016 (termed here PH-EPS) and investigated its immunomodulatory activity and its potential molecular mechanisms in RAW 264.7 macrophages.

\section{Materials and methods}

Antibodies and reagents. Antibodies targeting NF- $\mathrm{B}$ p65 (cat. no. ab32536), inhibitor of $\kappa \mathrm{B}$ (IкB)- $\alpha$ (cat. no. ab32518), p38 (cat. no. ab170099), phosphorylated (p-)p38 (cat. no. ab47363), ERK (cat. no. ab115799), p-ERK (cat. no. ab222493), inducible nitric oxide synthase (iNOS, cat. no. ab213987), TLR2 (cat. no. ab209217), TLR4 (cat. no. ab13556), JNK (cat.no. ab179461), p-JNK (cat. no. ab124956), Dectin-1 (cat. no. ab140039) and CD11b (also known as CR3, cat. no. ab133357) were purchased from Abcam. Lipopolysaccharide (LPS), fetal bovine serum (FBS), streptomycin, penicillin-G, the pyrrolidine dithiocarbamate (PDTC) and BAY11-7082 inhibitors, Dulbecco's modified Eagle's medium (DMEM), enhanced chemiluminescence (ECL) kit, and nitric oxide (NO) assay kit (Griess reagent) were obtained from Gibco (Thermo Fisher Scientific, Inc.). 3-(4,5-dimethylthiazol-2-yl)-2,5-diphenyltetrazolium bromide (MTT), dimethyl sulfoxide (DMSO), polymyxin B (PMB), FITC-dextran, and the inhibitors of p38 (SB203580), JNK (SP600125) and ERK (PD98059) were purchased from Sigma-Aldrich (Merck KGaA). Murine ELISA Kits for detection of tumor necrosis factor (TNF)- $\alpha$ (cat. no. EK0527) and interleukin (IL)-1 $\beta$ (cat. no. EK0394) were purchased from Wuhan Boster Biological Technology, Ltd.

Preparation of PH-EPS. The fungus strain P. lilacinus PH0016 was maintained in Hainan Provincial Key Laboratory of Tropical Medicine. Preparation of EPSs from P. lilacinus PH0016 was performed as previously described (15). In brief, Paecilomyces lilacinus PH0016 was cultured in Potato Dextrose Agar on a rotator at $180 \mathrm{rpm}$ at $28^{\circ} \mathrm{C}$ for 10 days Then, the concentrated supernatant of the culture was obtained using a rotary evaporator and was further processed by ethanol precipitation, dialysis and protein depletion. The crude polysaccharides were then purified through Sephadex G-75 and DEAE-Sepharose (Klamar). After being dialyzed and lyophilized, the purified PH-EPS was obtained. The PH-EPS was confirmed to be free of protein and nucleic acid by ultraviolet detection at absorbance of 260 and $280 \mathrm{~nm}$, respectively. The components of PH-EPS (32.3 kDa) included rhamnose, fucose, xylose, glucose, mannose and galactose, in which the relative molar ratio was 17.5:16.9:2.3:21.5:27.4:14.4, based on gas chromatography.

Cell culture. The mouse macrophage cell line RAW 264.7 was purchased from The Cell Bank of Type Culture Collection of Chinese Academy of Sciences. Cells at the logarithmic phase were cultured with or without PH-EPS (0-800 $\mu \mathrm{g} / \mathrm{ml})$ in DMEM supplemented with streptomycin $(100 \mu \mathrm{g} / \mathrm{ml})$, penicillin-G $(100 \mathrm{U} / \mathrm{ml})$ and $10 \%$ FBS in a standard humidified incubator (Sanyo Electric Co., Ltd.) at $37^{\circ} \mathrm{C}$ containing $5 \% \mathrm{CO}_{2}$.

MTT assay. RAW 264.7 cells $\left(4 \times 10^{5}\right.$ cells/ml) at logarithmic phase were cultured at $37^{\circ} \mathrm{C}$ with $5 \% \mathrm{CO}_{2}$ in 96 -well plates overnight. They were then treated with various doses of PH-EPS $(0-800 \mu \mathrm{g} / \mathrm{ml})$ or LPS $(1 \mu \mathrm{g} / \mathrm{ml})$ for $24 \mathrm{~h}$. Thereafter, MTT reagent $(5 \mathrm{mg} / \mathrm{ml}, 10 \mu \mathrm{l} /$ well) was added to the well at $37^{\circ} \mathrm{C}$ for another $4 \mathrm{~h}$. Finally, the supernatant was discarded, and DMSO (150 $\mu \mathrm{l})$ was added into each well for solubilizing the formazan. The absorbance of the dissolved solutions was detected at $490 \mathrm{~nm}$ using a microplate reader (EXL808; BioTek Instruments, Inc.).

NO production. The macrophage RAW 264.7 cells at logarithmic phase were cultured at $37^{\circ} \mathrm{C}$ with $5 \% \mathrm{CO}_{2}$ for 1 day and then incubated with PH-EPS $(0-600 \mu \mathrm{g} / \mathrm{ml})$ or LPS $(1 \mu \mathrm{g} / \mathrm{ml}$, as positive control) for a day. The NO production was detected using a commercially available Griess reagent kit (Molecular Probes; Thermo Fisher Scientific, Inc.). A sodium nitrite standard curve was established for calculating the concentration of nitrite and the $540 \mathrm{~nm}$ absorbance was recorded using a microplate reader.

Cytokine assay. RAW 264.7 macrophage cells at logarithmic phase were cultured and treated with PH-EPS $(0-600 \mu \mathrm{g} / \mathrm{ml})$ or LPS $(1 \mu \mathrm{g} / \mathrm{ml})$ for 1 day. The concentration of TNF- $\alpha$ and IL-1 $\beta$ in the supernatants of the cell culture was detected using commercially available ELISA kits from Wuhan Boster Biological Technology, Ltd.

Determination of dextran uptake by flow cytometry. The dextran uptake by RAW 264.7 cells was identified as in a previous study (15). RAW 264.7 cells $\left(5 \times 10^{5}\right.$ cells $/ \mathrm{ml}$ in each well) were cultured with PH-EPS $(0-600 \mu \mathrm{g} / \mathrm{ml})$ or LPS $(1 \mu \mathrm{g} / \mathrm{ml})$ for 1 day at $37^{\circ} \mathrm{C}$ with $5 \% \mathrm{CO}_{2}$ in 6 -well plates. Cells were collected, followed by suspension in $1 \mathrm{mg} / \mathrm{ml}$ FITC-labeled dextran (100 $\mu \mathrm{l} /$ well). Thereafter, cells were further cultured at $37^{\circ} \mathrm{C}$ with $5 \% \mathrm{CO}_{2}$ for $0.5 \mathrm{~h}$. Then cold PBS $(2 \mathrm{ml})$ mixed with $0.02 \%$ sodium azide and $1 \%$ human serum (Gibco; Thermo Fisher Scientific, Inc.) were added to each well to terminate the uptake of dextran. Finally, the RAW 264.7 cells were washed with cold PBS for three times and the level of the dextran uptake was indicated as the fluorescence intensity detected by flow cytometry (FACSCalibur; BD Biosciences) and analyzed by FlowJo software version 10 (FlowJo LLC).

Immunofluorescence analysis. The RAW 264.7 macrophage cells $\left(5 \times 10^{5}\right.$ cells $/ \mathrm{ml}$ in each well) were incubated on glass coverslips and treated with PH-EPS $(200 \mu \mathrm{g} / \mathrm{ml})$ or LPS ( $1 \mu \mathrm{g} / \mathrm{ml}$, for positive control) for $1 \mathrm{~h}$. Subsequently, the cells were rinsed with cold $\mathrm{PB}$ at least three times and fixed with $4 \%$ paraformaldehyde at $37^{\circ} \mathrm{C}$ for $30-60 \mathrm{~min}$. Thereafter, the cells were permeabilized with $0.2 \%$ Triton $\mathrm{X}-100$, blocked with bovine serum albumin $(5 \%$ in PBS; Gibco; Thermo Fisher Scientific, Inc.) at $37^{\circ} \mathrm{C}$ for $30 \mathrm{~min}$, and

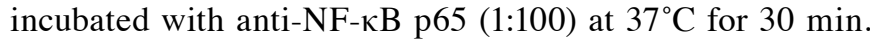
Then, the cells were thoroughly rinsed in PBS and incubated with a Cy3-labeled goat anti-rabbit IgG secondary antibody (cat. no. BA1032; Wuhan Boster Biological Technology, Ltd.) at $1: 100$ for $30 \mathrm{~min}$ at $37^{\circ} \mathrm{C}$. DAPI was used as a nuclear counterstain at $37^{\circ} \mathrm{C}$ for $30 \mathrm{~min}$. Images were captured via an Olympus FV300 confocal laser scanning microscope (Olympus Corporation). 
Western blotting. Western blotting was performed as described previously (23). Briefly, the RAW 264.7 cells at logarithmic phase were treated with PH-EPS $(0-600 \mu \mathrm{g} / \mathrm{ml})$ or LPS $(1 \mu \mathrm{g} / \mathrm{ml})$ for $24 \mathrm{~h}$, then the cells were washed three times with PBS and lysed in RIPA buffer (1 mM EDTA, $0.1 \%$ Triton $\mathrm{X}-100,50 \mathrm{mM}$ Tris, $1 \mathrm{mM}$ phenylmethylsulfonyl fluoride, $1 \%$ sodium deoxycholate and $150 \mathrm{mM} \mathrm{NaCl}$ ). The concentration of the protein in the supernatant was determined by a protein assay kit (bicinchoninic acid; Pierce, Thermo Fisher Scientific, Inc.). The supernatants were separated by $12 \%$ SDS-PAGE and the gel was then transferred onto PVDF membranes (EMD Millipore) using a mini transblot system (Bio-Rad Laboratories, Inc.). Thereafter, the PVDF membranes were blocked with $10 \%$ non-fat milk at $37^{\circ} \mathrm{C}$ for $2 \mathrm{~h}$, incubated with the aforementioned primary antibodies (see the Antibodies and Reagents section; diluted 1:100) overnight at $4^{\circ} \mathrm{C}$, followed by incubating with horseradish peroxidase-conjugated goat anti-rabbit IgG secondary antibodies (1:100; cat. no. ab205718; Abcam) for 1-2 $h$ at room temperature. Enhanced chemiluminescence (ECL) Western Blotting Substrate A and B (cat. no. AR1170; Wuhan Boster Biological Technology, Ltd.) were used at 1:1 for detecting target proteins and the semi-quantitated band densities were acquired using ImageJ 1.8.0 (National Institutes of Health).

Inhibition of MAPK and $N F-\kappa B$ pathways. Specific inhibitors were used for inhibiting the MAPK and NF- $\kappa \mathrm{B}$ pathways as described previously (15). In brief, p38 MAPK inhibitor (25 $\mu \mathrm{M}$ SB203580), NF- $\kappa \mathrm{B}$ inhibitors (10 $\mu \mathrm{M}$ BAY11-7082 or $50 \mu \mathrm{M}$ PDTC), ERK inhibitor (25 $\mu \mathrm{M}$ PD98059) and JNK inhibitor (25 $\mu \mathrm{M}$ SP600125) were used to pretreat the RAW 264.7 cells for $1 \mathrm{~h}$. Thereafter, the cells were treated with or without $1 \mu \mathrm{g} / \mathrm{ml} \mathrm{LPS} \mathrm{or} 200 \mu \mathrm{g} / \mathrm{ml} \mathrm{PH}$-EPS for 1 day at $37^{\circ} \mathrm{C}$. ELISA kits were then used to detect the levels of IL-1 $\beta$ and TNF- $\alpha$ in the supernatant.

Blocking experiments with antibodies. The roles of Dectin-1, CR3, TLR2 and TLR4 on the production of cytokines induced by PH-EPS were also investigated as described previously (15). Briefly, the cells were first incubated with $20 \mu \mathrm{g} / \mathrm{ml}$ blocking antibodies against Dectin-1, CR3, TLR2, or TLR4 for $2 \mathrm{~h}$. Subsequently, the cells were treated with $200 \mu \mathrm{g} / \mathrm{ml}$ PH-EPS and incubated for 1 day. ELISA kits were employed to determine the IL-1 $\beta$ and TNF- $\alpha$ in the supernatants.

Statistical analysis. Data analysis was performed using GraphPad Prism 6 software (GraphPad Software, Inc.). Non-parametric two-tailed Student's t-test was used to analyze the difference of data from two samples and one- or two-way ANOVA was used for comparing more than two samples followed by Bonferroni's post-hoc test. Values are presented as mean \pm standard deviation. $\mathrm{P}<0.05$ was considered to indicate a statistically significant difference.

\section{Results and Discussion}

Effect of PH-EPS on the RAW 264.7 cell viability. Since natural polysaccharides are less harmful and highly susceptible to biodegradation than synthetic polymers, interest in the potential of EPSs for immunostimulatory therapy has

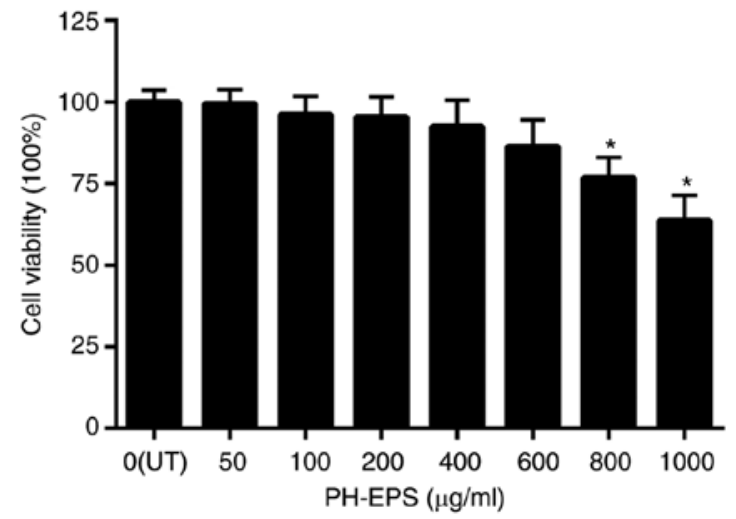

Figure 1. Effect of PH-EPS on the viability of RAW 264.7 cells. Cells were treated with various concentrations of PH-EPS for 1 day, and an MTT assay was used to determine cell viability. Data are expressed as mean \pm standard deviation of 6 experiments. " $\mathrm{P}<0.05$ vs. UT group. PH-EPS, exopolysaccharides derived from the fungus Paecilomyces lilacinus PH0016; UT, untreated.

increased sharply $(24,25)$. In recent years, many microbial EPSs with novel functional properties have been isolated (26). The surface localization enables the EPSs to interact with micro- and macro-organisms more easily. In addition, numerous polysaccharides isolated from natural sources are recognized as effective biological response modifiers with low toxicity, and used as safe and efficacious adjuvants in vaccines against pathogens and cancer (27). Considering that macrophages have an important role in the immune response against various stimuli of bacteria, the murine RAW 264.7 macrophage cell line was selected in the present study to investigate the potential immunomodulatory activity of PH-EPS. The cells were treated with different concentrations of PH-EPS for 1 day and the MTT assay was used to measure cell viability. It was found that treatment with PH-EPS concentrations of up to $600 \mu \mathrm{g} / \mathrm{ml}$ had no significant effect on the viability of RAW 264.7 cells (Fig. 1).

NO production and iNOS expression. Macrophages are activated by various factors, including bacterial LPS and proinflammatory cytokines. Many cytokines can be secreted by activated macrophages, including IL- $1 \beta$, TNF- $\alpha$ and other chemical mediators of inflammation such as NO (28). NO is produced by NO synthase, among which iNOS is the major contributor to NO production (29). As a significant intra- and extracellular messenger, NO participates in the elimination of microbes and tumor cells (29,30).

To identify whether PH-EPS could increase the production of NO, the RAW 264.7 cells were treated with $1 \mu \mathrm{g} / \mathrm{ml}$ LPS or $0-600 \mu \mathrm{g} / \mathrm{ml}$ PH-EPS. As presented in Fig. 2A, LPS treatment greatly increased the production of NO. PH-EPS treatment also induced significant NO production in a dose-dependent way (Fig. 2A). Considering that PH-EPS was isolated from the fungus $P$. lilacinus, there is a possibility that the production of NO in PH-EPS-treated RAW 264.7 cells may be related to endotoxin contamination. To rule out this possibility, PMB, which binds to the lipid A moiety, was used to inhibit the biological activity of the LPS, as described previously (15). PH-EPS and LPS were pretreated with $50 \mu \mathrm{g} / \mathrm{ml}$ PMB and then applied to the RAW 264.7 cells as aforementioned. The 

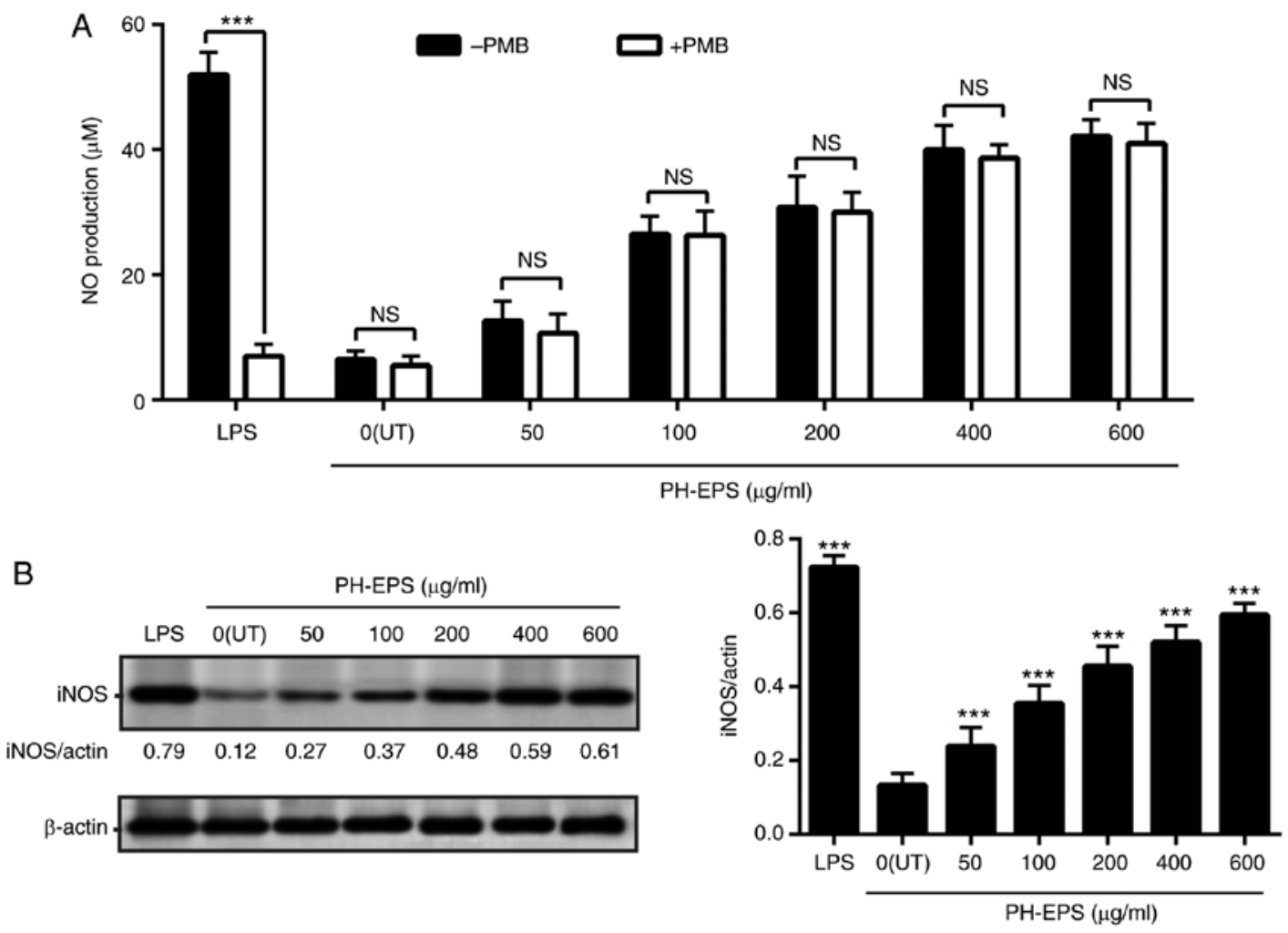

Figure 2. Effect of PH-EPS on iNOS expression and NO production. RAW 264.7 cells were treated with LPS $(1 \mu \mathrm{g} / \mathrm{ml})$ or the indicated dose of PH-EPS for 1 day. (A) NO levels in the supernatant were measured. ${ }^{* * *} \mathrm{P}<0.001$, with comparisons indicated by brackets. (B) iNOS protein expression was analyzed by western blotting and the protein ratios were calculated. ${ }^{* * *} \mathrm{P}<0.001$ vs. UT group. Data are expressed as mean \pm standard deviation of triplicate experiments. PH-EPS, exopolysaccharides derived from the fungus Paecilomyces lilacinus PH0016; iNOS, inducible NO synthase; NO, nitric oxide; LPS, lipopolysaccharide; UT, untreated; PMB, polymyxin B; NS, not significant.

results indicated that NO production induced by LPS was significantly inhibited after LPS was pretreated with PMB, but the PMB pretreatment had no effect on PH-EPS-induced NO production. Thus, it can be concluded that the PH-EPS itself, but not an endotoxin contamination, was the mediator of the NO production in macrophages.

To investigate whether a potential upregulation of iNOS was the underlying mechanism of the induced NO secretion in the PH-EPS-treated RAW 264.7 cells, the iNOS protein expression levels were measured by western blotting. The iNOS protein expression levels were significantly increased in the LPS-treated cells (Fig. 2B). PH-EPS treatment also significantly induced iNOS expression, similar to NO production, in PH-EPS-treated cells (Fig. 2B). These results demonstrated that PH-EPS could promote NO secretion via the upregulated iNOS expression in the RAW 264.7 cells.

PH-EPS enhances secretion of IL- $1 \beta$ and TNF- $\alpha$. IL- $1 \beta$ and TNF- $\alpha$ are two crucial proinflammatory cytokines produced by activated macrophages and are crucial for innate and adaptive immunities (28). IL- $1 \beta$ is produced in activated macrophages and it initiates a signaling cascade, leading to the transcription of various inflammatory cytokines. In addition, it can affect $\mathrm{B}$ cell proliferation and $\mathrm{T}$ cell maturation, and induce the expression of several inflammatory molecules, including NO, cyclooxygenase-2, prostaglandin $\mathrm{E}$ and phospholipase A2 $(31,32)$. As a multifunctional cytokine, TNF- $\alpha$ can initiate a cytokine cascade and induce the expression of immunoregulatory and inflammatory cytokines or other mediators in an autocrine manner (28). TNF- $\alpha$ secreted by activated macrophages is also a potential agent for cancer treatment through induction of tumor cell necrosis and apoptosis $(33,34)$.

Thus, in the present study, the IL- $1 \beta$ and TNF- $\alpha$ levels were measured using ELISA assays, in order to determine whether PH-EPS affected their secretion. As presented in Fig. 3, compared with the untreated control group $(0 \mu \mathrm{g} / \mathrm{ml})$, there was a significant increase in the levels of IL-1 $\beta$ and TNF- $\alpha$ in the LPS-treated group (positive control). For the PH-EPS-treated groups, the levels of IL-1 $\beta$ and TNF- $\alpha$ were dose-dependently increased (Fig. 3). These results indicated that PH-EPS had the modulatory capacity of activating the RAW 264.7 cells to produce IL-1 $\beta$ and TNF- $\alpha$.

PH-EPS enhances phagocytic uptake in macrophage cells. Phagocytosis by macrophages is a vital function of innate immunity, ingesting abnormal cells, cell debris, foreign particles and microorganisms. A key characteristic of activated macrophages is the increased phagocytic capability (35). Therefore, to investigate whether PH-EPS could affect macrophage phagocytosis, the RAW 264.7 cells were co-incubated with FITC-labeled dextran and PH-EPS for 1 day, while LPS was used as a positive control. The fluorescent intensity in the cells was then detected in order to evaluate the effects of PH-EPS or LPS treatment on the phagocytic abilities of macrophages. Compared with the untreated control group, the fluorescent intensities in LPS- and PH-EPS-treated RAW 264.7 cells were significantly increased. 

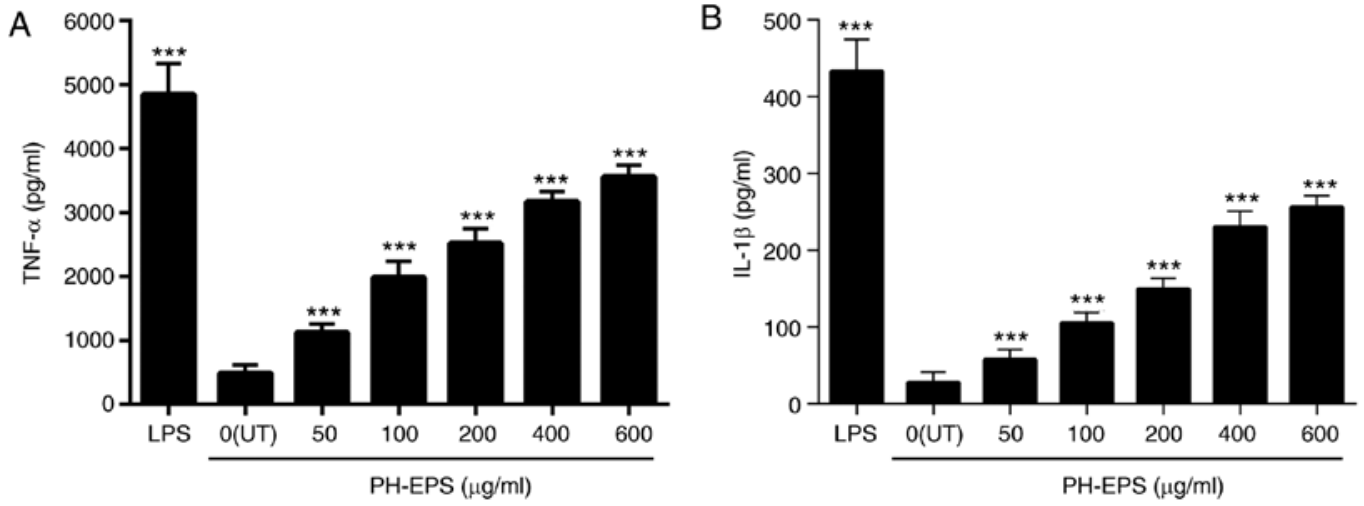

Figure 3. Effect of PH-EPS on the secretion of IL-1 $\beta$ and TNF- $\alpha$. RAW 264.7 cells were treated with LPS (1 $\mu \mathrm{g} / \mathrm{ml})$ or the indicated dose of PH-EPS for 1 day. (A) TNF- $\alpha$ and (B) IL-1 $\beta$ levels in the culture media were determined by ELISA. Data are expressed as mean \pm standard deviation of 5 replicates. ${ }_{* * * *} \mathrm{P}<0.001$ vs. UT group. PH-EPS, exopolysaccharides derived from the fungus Paecilomyces lilacinus PH0016; IL, interleukin; TNF, tumor necrosis factor; LPS, lipopolysaccharide; UT, untreated.
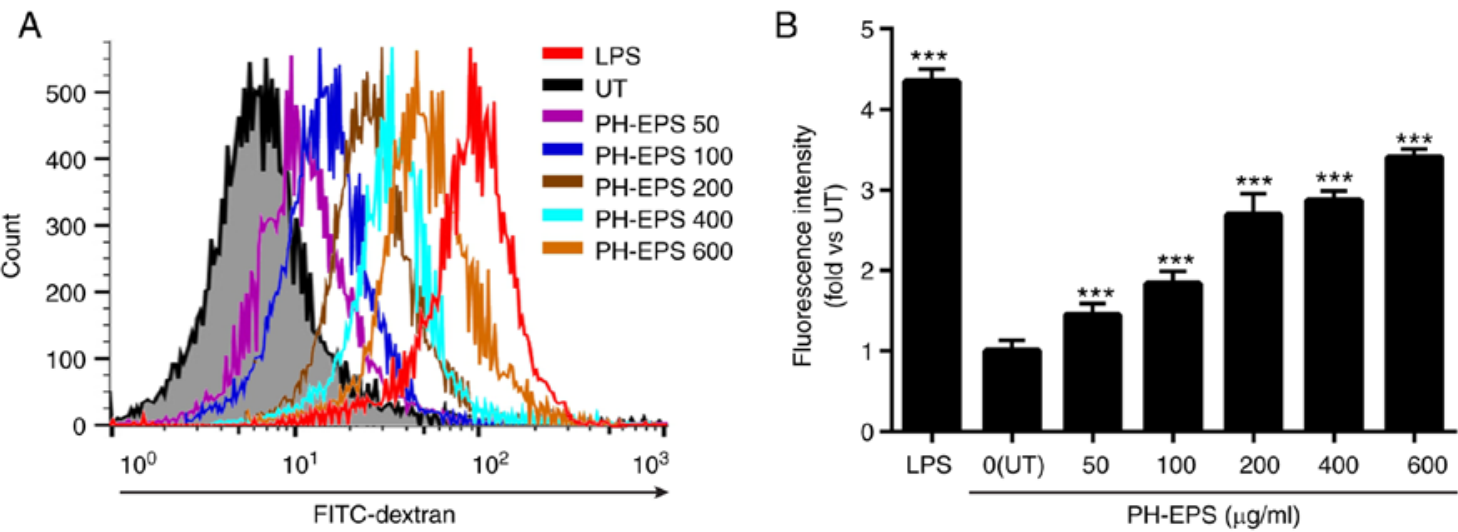

Figure 4. Effect of PH-EPS on phagocytic uptake. The phagocytic uptake of FITC-labeled dextran in RAW 264.7 cells was determined by flow cytometry. (A) Representative plots. (B) Quantitative histogram analysis about the phagocytic uptake of FITC-dextran in the experimental groups. Data are expressed as mean \pm standard deviation of 4 replicates. ${ }^{* * *} \mathrm{P}<0.001$ vs. UT group. PH-EPS, exopolysaccharides derived from the fungus Paecilomyces lilacinus $\mathrm{PH} 0016$; FITC, fluorescein isothiocyanate; UT, untreated; LPS, lipopolysaccharide.

As presented in Fig. 4, LPS-treated cells had the strongest increase of fluorescent intensity. PH-EPS-treated cells had a dose-dependent increase of fluorescent intensity (Fig. 4). These results demonstrated that PH-EPS could activate macrophages to enhance their capability of phagocytosis.

$P H-E P S$ induces $N F-\kappa B$ activation and $I \kappa B-\alpha$ degradation. $\mathrm{NF}-\kappa \mathrm{B}$, composed of a family of transcription factors, serves a key role in immunity, inflammation, cell survival, proliferation and differentiation (10). Inactive $\mathrm{NF}-\kappa \mathrm{B}$ is a complex containing $\mathrm{I} \kappa \mathrm{B}-\alpha, \mathrm{p} 50$ and p65. The degradation, but not phosphorylation, of I $\kappa$ B- $\alpha$ by stimuli such as LPS or PH-EPS is the first step of activation of $N F-\kappa B$, leading to phosphorylation of p50 and p65. Thereafter, the p-p50 and p-p65 subunits translocate from the cytoplasm into the nucleus, where they regulate different target genes $(8,9,36)$. During this process, I $\kappa \mathrm{B}-\alpha$ is degraded but not phosphorylated.

In order to investigate the role of the NF- $\mathrm{B}$ p 65 signaling pathway in the PH-EPS-activated macrophages, immunofluorescence analysis was performed to observe whether the translocation of $\mathrm{NF}-\kappa \mathrm{B}$ p 65 in the nucleus occurred. As expected, NF- $\kappa$ B p65 in the untreated RAW 264.7 cells was mainly localized in the cytoplasm, while NF- $\kappa$ B p65 obviously localized in the nucleus following treatment with $200 \mu \mathrm{g} / \mathrm{ml}$ PH-EPS or $1 \mu \mathrm{g} / \mathrm{ml}$ LPS (Fig. 5A). In addition, compared with the untreated group, the protein expression levels of I $\mathrm{B}-\alpha$ were significantly reduced in the cells treated with PH-EPS in a dose-dependent way; this reduction was also found in the LPS-treated positive control group (Fig. 5B). These results indicated that I $\kappa \mathrm{B}-\alpha$ was degraded in a dose-dependent manner in PH-EPS-treated macrophages.

To further confirm that PH-EPS-mediated macrophage activation was associated with $\mathrm{NF}-\kappa \mathrm{B}$ signaling, $\mathrm{NF}-\kappa \mathrm{B}$ inhibitors (BAY11-7082 and PDTC) were used to block $N F-\kappa B$ signaling and then the levels of IL-1 $\beta$ and TNF- $\alpha$ were detected. Compared with unblocked cells, IL-1 $\beta$ and TNF- $\alpha$ levels were significantly decreased in RAW 264.7 cells following NF- $\kappa \mathrm{B}$ inhibition (Fig. $5 \mathrm{C}$ and D). Together, the present results demonstrated that the $\mathrm{NF}-\kappa \mathrm{B}$ signaling pathway was associated with IL- $1 \beta / \mathrm{TNF}-\alpha$ induction and macrophage activation.

PH-EPS promotes phosphorylation of MAPKs. MAPKs are serine-threonine kinases and MAPK phosphorylation can 

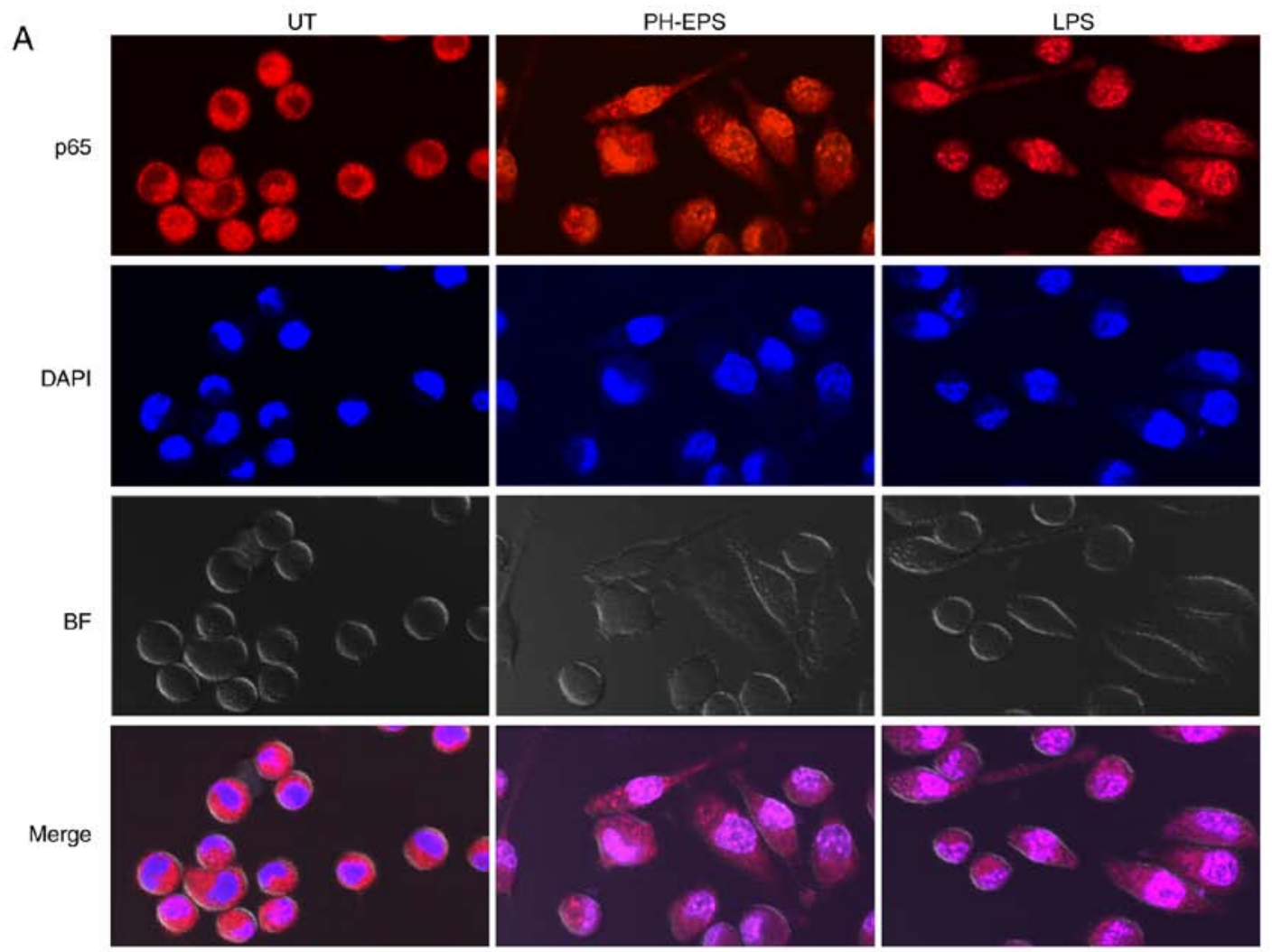

B
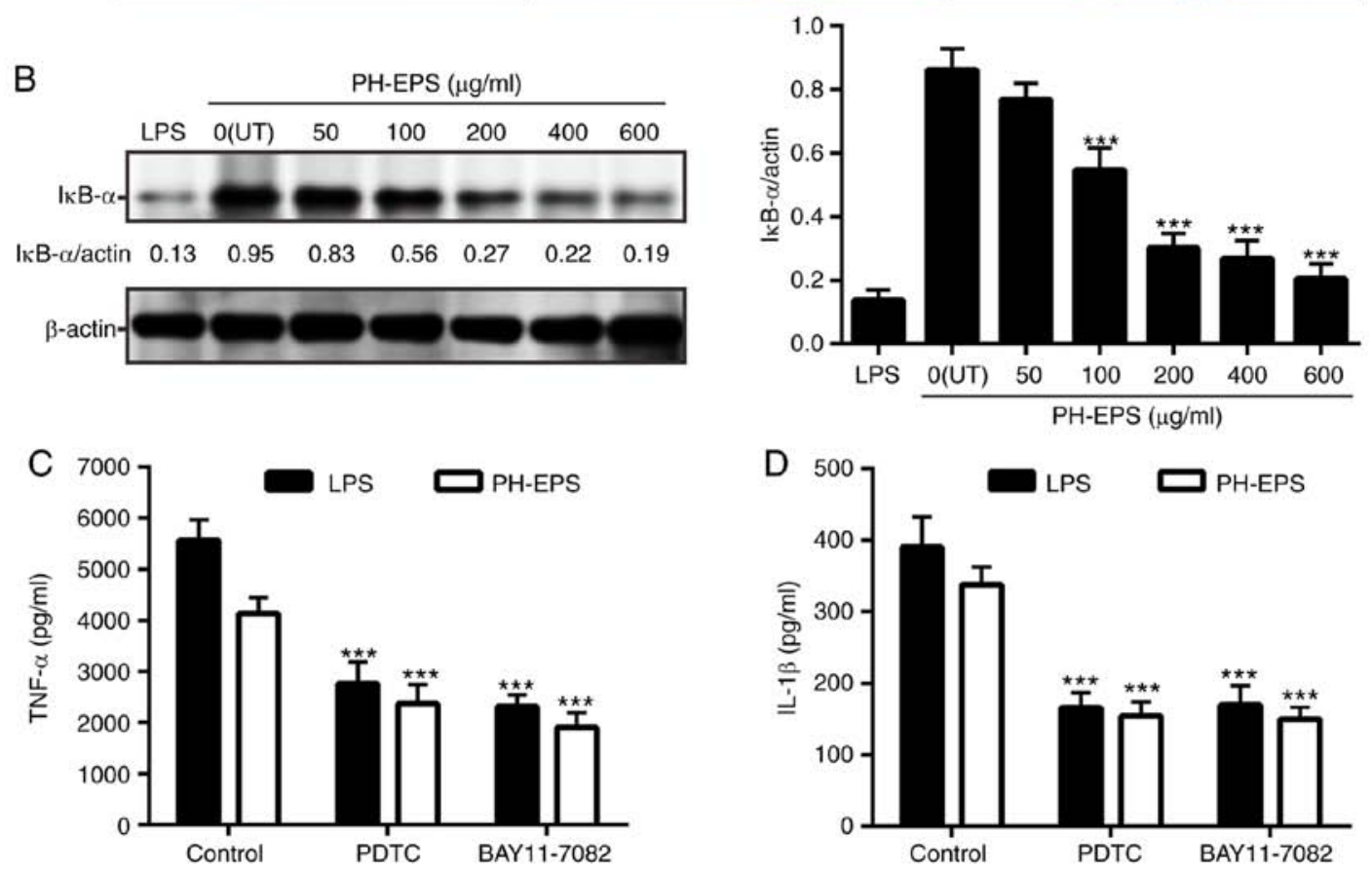

Figure 5. Effect of PH-EPS on NF-кB signaling pathway. (A) Representative images (magnification, x600) captured by confocal laser scanning microscopy.

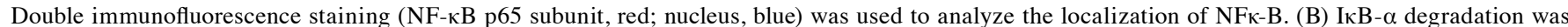
analyzed by western blotting. Data are expressed as mean \pm standard deviation of 3 replicates. ${ }^{* * * *} \mathrm{P}<0.001$ vs. UT group. (C) Effect of NF- $\mathrm{kB}$ inhibitors on the TNF- $\alpha$ and (D) IL-1 $\beta$ secretion induced by LPS or PH-EPS. Data are expressed as mean \pm standard deviation of 6 replicates. ${ }^{* * *} \mathrm{P}<0.001$ vs. control group. PH-EPS, exopolysaccharides derived from the fungus Paecilomyces lilacinus PH0016; NF, nuclear factor; IкB, inhibitor of $\kappa \mathrm{B}$; TNF, tumor necrosis factor; IL, interleukin; LPS, lipopolysaccharide; UT, untreated.

lead to the activation of NF- $\mathrm{KB}$ signaling following diverse extracellular stimuli, such as LPS, polysaccharides and proinflammatory cytokines (37). At present, ERK, JNK and p38 are considered to be the major cascades related to MAPK activation. These MAPK-related pathways are important in signal transduction, can regulate cytokine release and affect multiple cell functions (38). Several studies have reported that polysaccharides and LPS can result in the phosphorylation of $\mathrm{p} 38$, JNK and ERK, and subsequently in the cytokine secretion and NO release, in activated macrophages (39-41). 
A

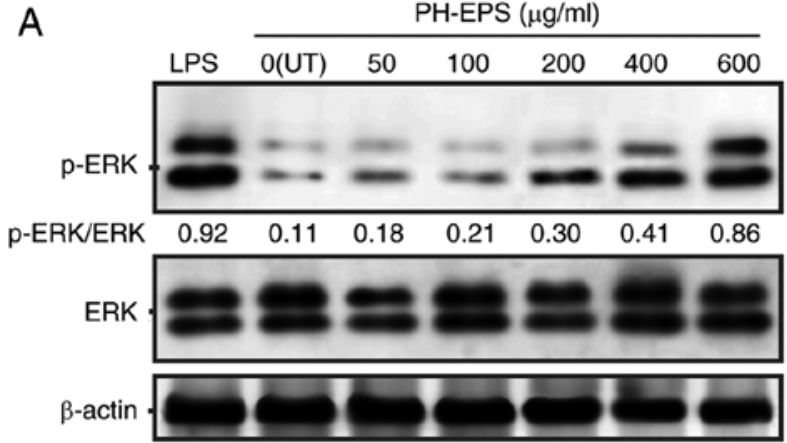

B

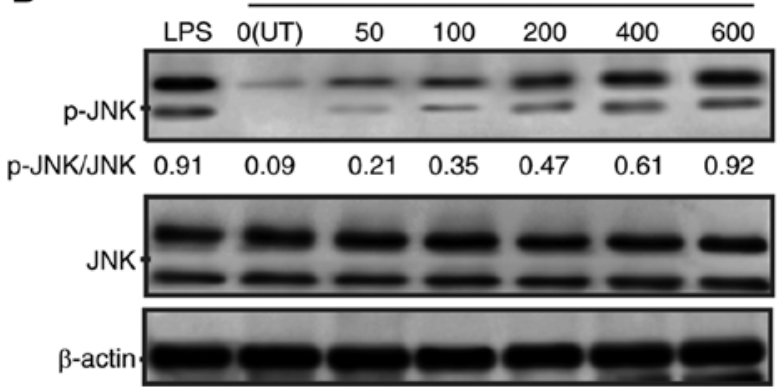

C
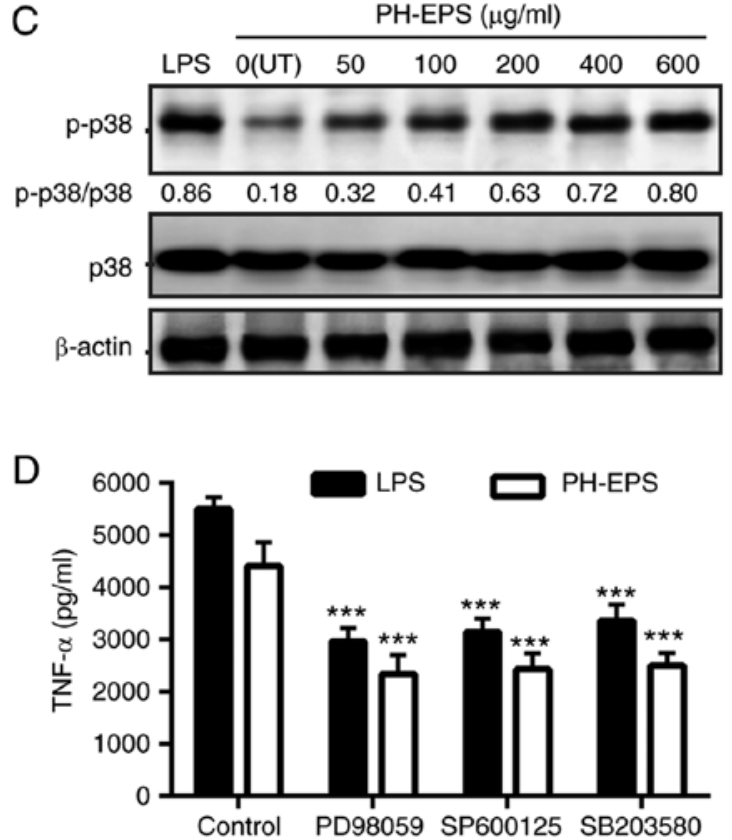
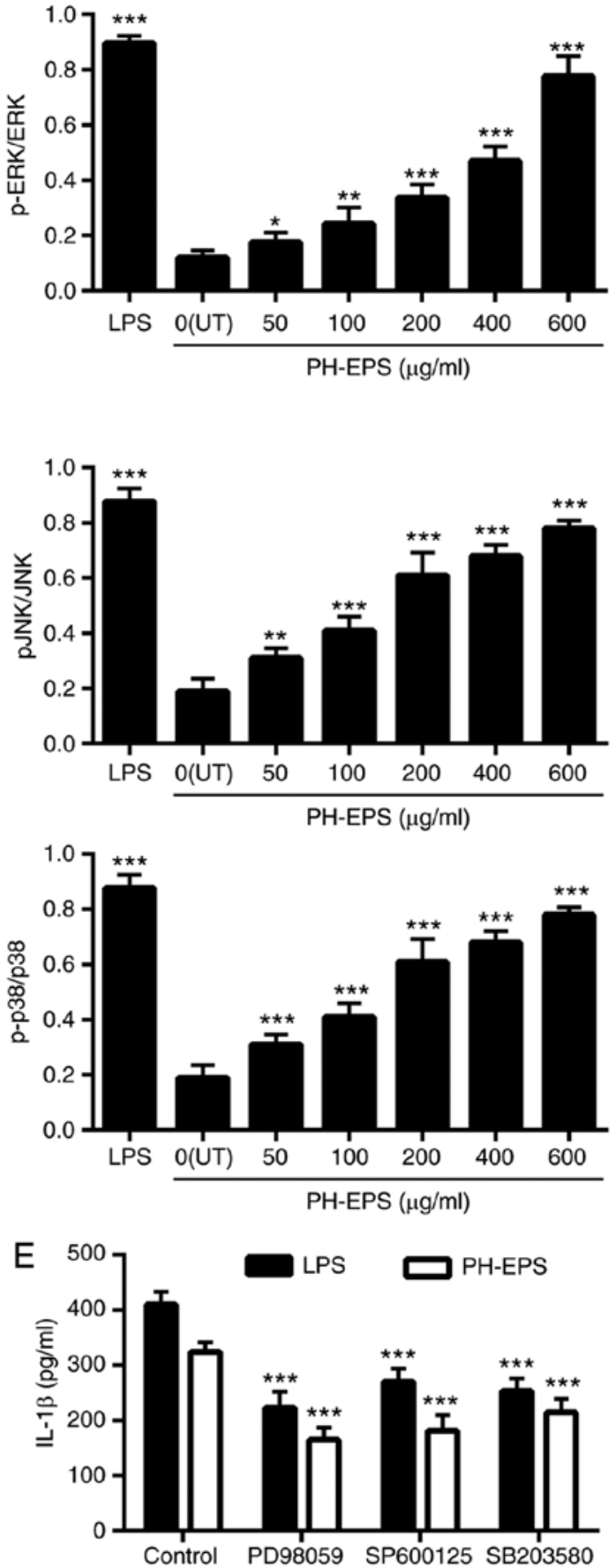

Figure 6. Effect of PH-EPS on MAPK signaling pathway. RAW 264.7 cells were cultured with the indicated dose of PH-EPS or LPS (1 $\mu$ g/ml) for 1 day. (A) Protein expression levels of p-ERK, (B) p-JNK and (C) p-p38 were normalized to total ERK, JNK, and p38, respectively. Data are expressed as mean \pm standard deviation of 3 replicates. ${ }^{*} \mathrm{P}<0.05,{ }^{* *} \mathrm{P}<0.01$ and ${ }^{* * *} \mathrm{P}<0.001$ vs. UT group. (D) RAW 264.7 cells were pretreated with the indicated MAPK inhibitors for $2 \mathrm{~h}$, followed by incubation with LPS $(1 \mu \mathrm{g} / \mathrm{ml})$ or PH-EPS $(200 \mu \mathrm{g} / \mathrm{ml})$. Levels of TNF- $\alpha$ and (E) IL-1 $\beta$ were determined by ELISA. Data are expressed as mean \pm standard deviation of 4 replicates. ${ }^{*} \mathrm{P}<0.05,{ }^{* *} \mathrm{P}<0.01$ and ${ }^{* * * *} \mathrm{P}<0.001$ vs. control group. PH-EPS, exopolysaccharides derived from the fungus Paecilomyces lilacinus PH0016; MAPK, mitogen-activated protein kinase; p-, phosphorylated; LPS, lipopolysaccharide; TNF, tumor necrosis factor; IL, interleukin.

The present study investigated whether MAPK signaling pathways were associated with the macrophage activation by PH-EPS treatment. The protein expression levels of ERK, JNK and p38, and their phosphorylated counterparts, were determined in the PH-EPS-treated cells via western blotting. Compared with the untreated control group, the levels of p-ERK, p-JNK and p-p38 in the PH-EPS-treated cells were significantly enhanced (Fig. 6A-C). In the LPS-treated cells, the levels of p-ERK, p-JNK and p-p38 were also significantly increased. In addition, to further verify that MAPK phosphorylation was required for macrophage activation, the levels of IL-1 $\beta$ and TNF- $\alpha$ in cells co-treated with MAPK inhibitors were detected by ELISA. As presented in Fig. 6D and E, when the phosphorylation of ERK, JNK and p38 in LPS or PH-EPS-treated RAW 264.7 cells was inhibited by PD98059, SP600125 and SB203580, respectively, 

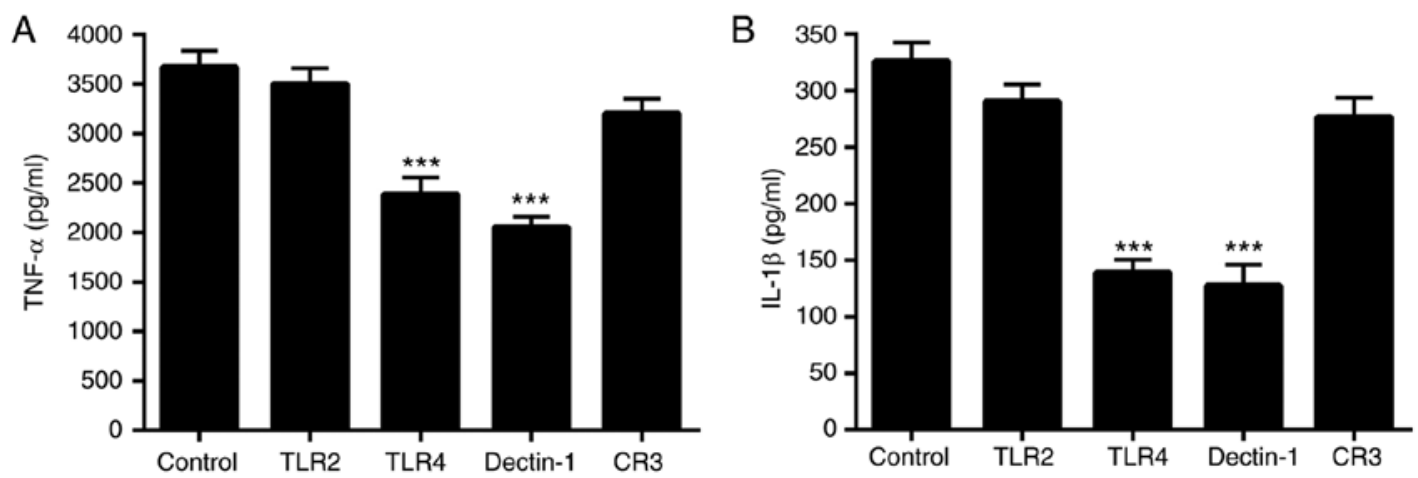

Figure 7. Effect of anti-PRR antibodies on cytokine secretion in PH-EPS-treated RAW264.7 cells. Blocking antibodies against the PRRs TLR2, TLR4, CR3 and Dectin-1 $(20 \mu \mathrm{g} / \mathrm{ml})$ were used to pretreat RAW 264.7 cells for $1 \mathrm{~h}$, and then the cells were incubated with PH-EPS (200 $\mu \mathrm{g} / \mathrm{ml})$ for $24 \mathrm{~h}$. (A) Levels of TNF- $\alpha$ and (B) IL-1 $\beta$ in the supernatants were determined by ELISA. Data are expressed as mean \pm standard deviation of 4 replicates. ${ }^{* * *} \mathrm{P}<0.001 \mathrm{vs}$. control group. PRR, pattern recognition receptor; PH-EPS, exopolysaccharides derived from the fungus Paecilomyces lilacinus PH0016; TLR, Toll-like receptor; $\mathrm{CR}$, complement receptor; TNF, tumor necrosis factor; IL, interleukin.

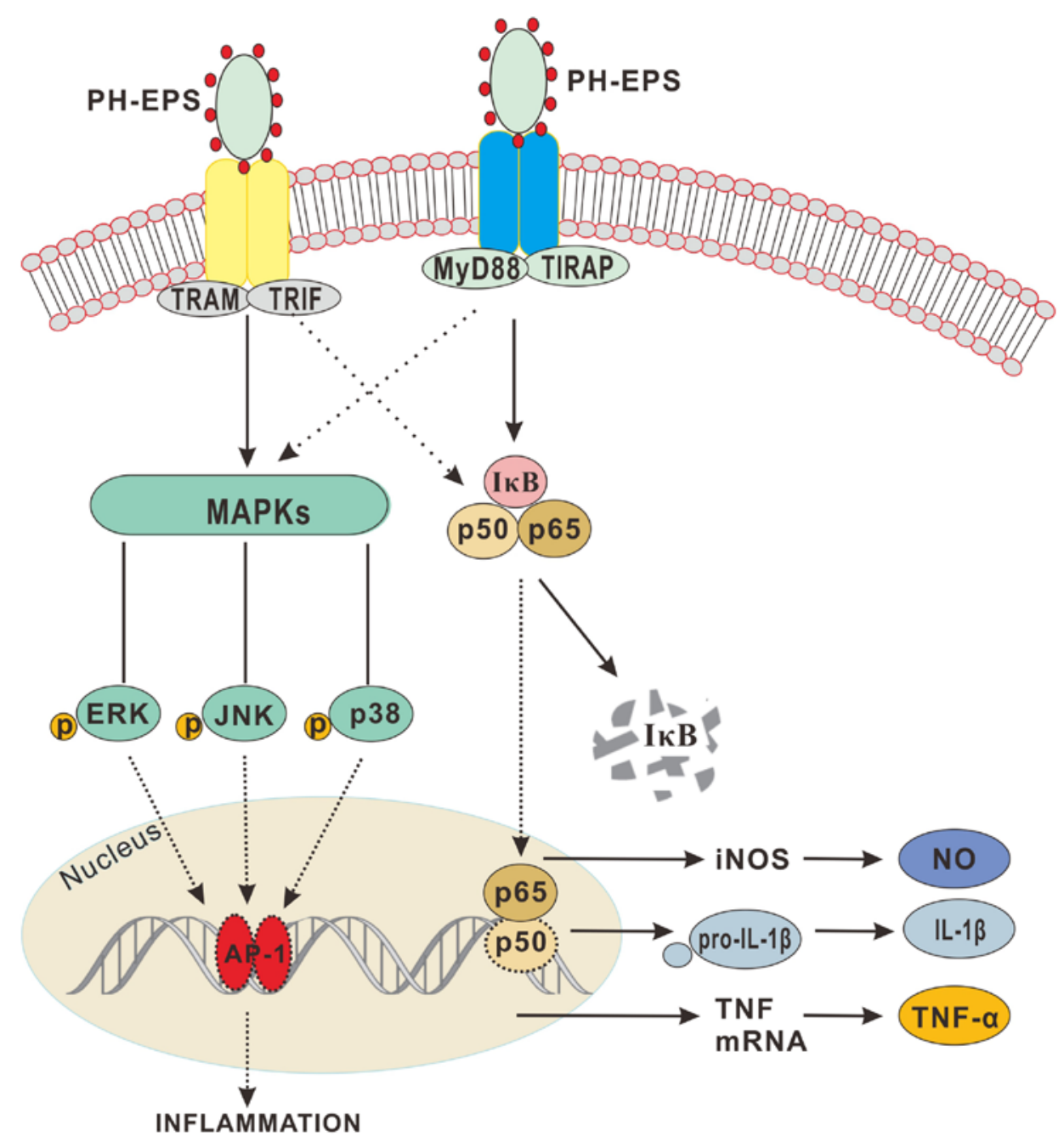

Figure 8. PH-EPS modulates the activation of RAW264.7 cells through the TLR4(Dectin-1)/NF-kB/MAPK pathway. PH-EPS binds to TLR4 and Dectin-1, which further activate the NF- $\mathrm{KB}$ and MAPK signaling pathways, respectively, resulting in the enhanced production of NO, and secretion of the proinflammation cytokines TNF- $\alpha$ and IL-1 $\beta$. PH-EPS, exopolysaccharides derived from the fungus Paecilomyces lilacinus PH0016; TLR, Toll-like receptor; NF, nuclear factor; MAPK, mitogen-activated protein kinase; NO, nitric oxide; TNF, tumor necrosis factor; IL, interleukin.

the secreted levels of IL-1 $\beta$ and TNF- $\alpha$ were significantly reduced. These results indicated that MAPKs (ERK, JNK and p38) participated in macrophage activation following PH-EPS treatment.
PH-EPS enhances secretion of IL- $1 \beta$ and TNF- $\alpha$ in RAW 264.7 cells via TLR4 and Dectin-1. Since polysaccharides are large molecules that cannot penetrate the cell membrane directly, it is impossible for polysaccharides to modulate 
immune response and intracellular events through interaction with intracellular target molecules. Therefore, it is reasonable to hypothesize that receptor binding on the cell surface may be one of the pathways by which PH-EPS acts on macrophages. To recognize various components on the fungal cell wall, macrophages express PRRs on their surface through which pathogen-associated molecular patterns can be recognized (42). Recent studies have demonstrated that PRRs such as TLR4, TLR2, CR3 and Dectin-1 have significant roles in macrophage activation when being exposed to polysaccharides (14,43-45).

To investigate whether TLR4, TLR2, CR3 and Dectin-1 were involved in the activation of the PH-EPS-treated RAW 264.7 cells, the functions of TLR4, TLR2, CR3 and Dectin-1 were blocked by their corresponding monoclonal antibodies and then the cells were treated with PH-EPS. Thereafter, IL-1 $\beta$ and TNF- $\alpha$ levels in the cell supernatants were determined. The results demonstrated that blocking TLR4 and Dectin-1 significantly inhibited the IL- $1 \beta$ and TNF- $\alpha$ secretion in PH-EPS-treated cells compared with the unblocked control group (Fig. 7). By contrast, blocking TLR2 and CR3 failed to inhibit the IL-1 $\beta$ and TNF- $\alpha$ secretion (Fig. 7). These results indicated that TLR4 and Dectin-1 may be the direct receptors of PH-EPS involved in PH-EPS-induced macrophage activation.

In summary, the results of the present study demonstrated that PH-EPS has the immunostimulatory capability of activating RAW 264.7 cells, as evidenced by augmented expression of NO, IL- $1 \beta$ and TNF- $\alpha$, and by enhanced phagocytosis ability. In addition, the results indicated that Dectin-1 and TLR4 may be two potential receptors that PH-EPS can directly bind, thus activating the NF- $\mathrm{NB}$ and MAPK signaling pathways. The proposed mechanism is summarized in Fig. 8. The current study demonstrated that PH-EPS may be a promising adjuvant or antitumor agent with immunomodulatory activity.

\section{Acknowledgements}

Not applicable.

\section{Funding}

The present study was supported by the National Natural Science Foundation of China (grant nos. 81560006, 81460020, 81460557,81560572 and 81673346).

\section{Availability of data and materials}

The datasets used and/or analyzed during the present study are available from the corresponding author on reasonable request.

\section{Authors' contributions}

Conception of the study was by FH and YL. CH, CW, HL, MZ, YL and GT performed the experiments. Data collection and analysis were performed by $\mathrm{CH}, \mathrm{CW}, \mathrm{HL}$ and GT. The original draft of the manuscript was by $\mathrm{CH}$ and it was rewritten and edited by GT. All authors read and approved the final manuscript.

\section{Ethics approval and consent to participate}

Not applicable.

\section{Patient consent for publication}

Not applicable.

\section{Competing interests}

The authors declare that they have no competing interests.

\section{References}

1. Gordon S and Plüddemann A: Tissue macrophages: Heterogeneity and functions. BMC Biol 15: 53, 2017.

2. Varin A and Gordon S: Alternative activation of macrophages: Immune function and cellular biology. Immunobiology 214: 630-641, 2009.

3. Navegantes KC, de Souza Gomes R, Pereira PAT, Czaikoski PG, Azevedo CHM and Monteiro MC: Immune modulation of some autoimmune diseases: The critical role of macrophages and neutrophils in the innate and adaptive immunity. J Transl Med 15: 36, 2017.

4. Mosser DM and Edwards JP: Exploring the full spectrum of macrophage activation. Nat Rev Immunol 8: 958-969, 2008.

5. Kim HS, Kim YJ, Lee HK, Ryu HS, Kim JS, Yoon MJ, Kang JS, Hong JT, Kim Y and Han SB: Activation of macrophages by polysaccharide isolated from Paecilomyces cicadae through toll-like receptor 4 . Food Chem Toxicol 50: 3190-3197, 2012.

6. Li J, Qian W, Xu Y, Chen G, Wang G, Nie S, Shen B, Zhao Z, Liu C and Chen K: Activation of RAW 264.7 cells by a polysaccharide isolated from Antarctic bacterium Pseudoaltermonas sp. S-5. Carbohydr Polym 130: 97-103, 2015.

7. Laplante P, Amireault P, Subang R, Dieudé M, Levine JS and Rauch J: Interaction of $\beta 2$-glycoprotein I with lipopolysaccharide leads to Toll-like receptor 4 (TLR4)-dependent activation of macrophages. J Biol Chem 286: 42494-42503, 2011.

8. Chen LF and Greene WC: Regulation of distinct biological activities of the NF-kappaB transcription factor complex by acetylation. J Mol Med (Berl) 81: 549-557, 2003.

9. Hayden MS and Ghosh S: Signaling to NF-kappaB. Genes Dev 18: 2195-2224, 2004

10. Baldwin AS Jr: The NF-kappa B and I kappa B proteins: New discoveries and insights. Annu Rev Immunol 14: 649-683, 1996.

11. Lee JS, Kwon DS, Lee KR, Park JM, Ha SJ and Hong EK: Mechanism of macrophage activation induced by polysaccharide from Cordyceps militaris culture broth. Carbohydr Polym 120: 29-37, 2015.

12. Ayoub SS, Botting RM, Joshi AN, Seed MP and Colville-Nash PR: Activation of macrophage peroxisome proliferator-activated receptor-gamma by diclofenac results in the induction of cyclooxygenase- 2 protein and the synthesis of anti-inflammatory cytokines. Mol Cell Biochem 327: 101-110, 2009.

13. Skeen MJ, Miller MA, Shinnick TM and Ziegler HK: Regulation of murine macrophage IL-12 production. Activation of macrophages in vivo, restimulation in vitro, and modulation by other cytokines. J Immunol 156: 1196-1206, 1996.

14. Takeuchi O and Akira S: Toll-like receptors; their physiological role and signal transduction system. Int Immunopharmacol 1: 625-635, 2001.

15. Wang G, Zhu L, Yu B, Chen K, Liu B, Liu J, Qin G, Liu C, Liu H and Chen K: Exopolysaccharide from Trichoderma pseudokoningii induces macrophage activation. Carbohydr Polym 149: 112-120, 2016.

16. Paynich ML,Jones-Burrage SEandKnight KL:Exopolysaccharide from bacillus subtilis induces anti-inflammatory M2 macrophages that prevent T cell-mediated disease. J Immunol 198: 2689-2698, 2017.

17. Zhu Y, Wang C, Jia S, Wang B, Zhou K, Chen S, Yang Y and Liu S: Purification, characterization and antioxidant activity of the exopolysaccharide from Weissella cibaria SJ14 isolated from Sichuan paocai. Int J Biol Macromol 115: 820-828, 2018. 
18. Yamac M, Kanbak G, Zeytinoglu M, Bayramoglu G, Senturk H and Uyanoglu M: Hypoglycemic effect of Lentinus strigosus (Schwein.) Fr. crude exopolysaccharide in streptozotocin-induced diabetic rats. J Med Food 11: 513-517, 2008.

19. Wang YX, Hu HY, Yang W, et al: The in vitro anti-HSV-1 action of an EPS extract made from Paecilomyces lilacinus isolated from mangr soil. J Pathog Biol (China) 12: 5-9, 2014 (In Chinese).

20. Li GJ, Chang C, Ge TT, et al: Anti-HSV-1 activity in vitro of extracellular polysaccharides from Paecilomyces Lilacinuson isolated from mangrove. Shanxi Med J (China) 46: 123-126, 2017 (In Chinese).

21. Hu HY, Wang HM, Lin YZ, Chang CH, Yang W and Wang YX: Effects of extracellular polysaccharides from Paecilomyces Lilacinuson on function of mouse bone marrow-derived dendritic cells. Chin J Immunol 33: 212-216, 2017 (In Chinese).

22. Peixoto E, Oliveira JC, Antas PR and Borba CM: In-vitro study of the host-parasite interactions between mouse macrophages and the opportunistic fungus Paecilomyces lilacinus. Ann Trop Med Parasitol 104: 529-534, 2010.

23. Huang FY, Huang FR, Chen B, Liu Q, Wang H, Zhou SL, Zhao HG, Huang YH, Lin YY and Tan GH: Microencapsulation of tumor lysates and live cell engineering with MIP-3 $\alpha$ as an effective vaccine. Biomaterials 53: 554-565, 2015.

24. Liang TW and Wang SL: Recent advances in exopolysaccharides from Paenibacillus spp.: Production, isolation, structure, and bioactivities. Mar Drugs 13: 1847-1863, 2015.

25. Liu J, Wang X, Pu H, Liu S, Kan J and Jin C: Recent advances in endophytic exopolysaccharides: Production, structural characterization, physiological role and biological activity. Carbohydr Polym 157: 1113-1124, 2017.

26. Moscovici M: Present and future medical applications of microbial exopolysaccharides. Front Microbiol 6: 1012, 2015.

27. Li P and Wang F: Polysaccharides: Candidates of promising vaccine adjuvants. Drug Discov Ther 9: 88-93, 2015.

28. Glucksam-Galnoy Y, Sananes R, Silberstein N, Krief P, KravchenkoVV,MeijlerMMandZorT:Thebacterialquorum-sensing signal molecule N-3-oxo-dodecanoyl-L-homoserine lactone reciprocally modulates pro- and anti-inflammatory cytokines in activated macrophages. J Immunol 191: 337-344, 2013.

29. Kleinert H, Schwarz PM and Forstermann U: Regulation of the expression of inducible nitric oxide synthase. Biol Chem 384 1343-1364, 2003.

30. Nworu CS, Ihim SA, Okoye FB, Esimone CO, Adikwu MU and Akah PA: Immunomodulatory and immunorestorative activities of $\beta$-D-glucan-rich extract and polysaccharide fraction of mushroom, Pleurutus tuberregium. Pharm Biol 53: 1555-1566, 2015.

31. Gupta $P$ and Barthwal MK: IL-1 $\beta$ genesis: The art of regulating the regulator. Cell Mol Immunol 15: 998-1000, 2018.

32. Dinarello CA: Immunological and inflammatory functions of the interleukin-1 family. Annu Rev Immunol 27: 519-550, 2009.

33. Yan Q, Chen X, Gong H, Qiu P, Xiao X, Dang S, Hong A and Ma Y: Delivery of a TNF- $\alpha$-derived peptide by nanoparticles enhances its antitumor activity by inducing cell-cycle arrest and caspase-dependent apoptosis. FASEB J 30: fj201800377R, 2018 (Epub ahead of print).
34. Bergers $\mathrm{G}$ and Benjamin LE: Tumorigenesis and the angiogenic switch. Nat Rev Cancer 3: 401-410, 2003.

35. Henneke P and Golenbock DT: Phagocytosis, innate immunity, and host-pathogen specificity. J Exp Med 199: 1-4, 2004.

36. Hatada EN, Krappmann D and Scheidereit C: NF-kappaB and the innate immune response. Curr Opin Immunol 12: 52-58, 2000.

37. Ruimi N, Rwashdeh H, Wasser S, Konkimalla B, Efferth T, Borgatti M, Gambari R and Mahajna J: Daedalea gibbosa substances inhibit LPS-induced expression of iNOS by suppression of NF-kappaB and MAPK activities in RAW 264.7 macrophage cells. Int J Mol Med 25: 421-432, 2010.

38. Johnson GL and Lapadat R: Mitogen-activated protein kinase pathways mediated by ERK, JNK, and p38 protein kinases. Science 298: 1911-1912, 2002.

39. Jones E, Adcock IM, Ahmed BY and Punchard NA: Modulation of LPS stimulated NF-kappaB mediated Nitric Oxide production by PKCepsilon and JAK2 in RAW macrophages. J Inflamm (Lond) 4: 23, 2007.

40. Yoon YD, Kang JS, Han SB, Park SK, Lee HS, Kang JS and Kim HM: Activation of mitogen-activated protein kinases and AP-1 by polysaccharide isolated from the radix of Platycodon grandiflorum in RAW 264.7 cells. Int Immunopharmacol 4: 1477-1487, 2004

41. Park JM, Kunieda T and Kubo T: The activity of Mblk-1, a mushroom body-selective transcription factor from the honeybee, is modulated by the ras/MAPK pathway. J Biol Chem 278 18689-18694, 2003.

42. Agustinho DP, de Oliveira MA, Tavares AH, Derengowski L, Stolz V, Guilhelmelli F, Mortari MR, Kuchler K and Silva-Pereira I: Dectin-1 is required for miR155 upregulation in murine macrophages in response to Candida albicans. Virulence 8: 41-52, 2017.

43. Cohen N, Stolarsky-Bennun M, Amir-Kroll H, Margalit R, Nussbaum G, Cohen-Sfady M, Pevsner-Fischer M, Fridkin M, Bercovier H, Eisenbach L, et al: Pneumococcal capsular polysaccharide is immunogenic when present on the surface of macrophages and dendritic cells: TLR4 signaling induced by a conjugate vaccine or by lipopolysaccharide is conducive. J Immunol 180: 2409-2418, 2008.

44. Herre J, Gordon S and Brown GD: Dectin-1 and its role in the recognition of beta-glucans by macrophages. Mol Immunol 40: 869-876, 2004

45. Le Cabec V, Carreno S, Moisand A, Bordier C and Maridonneau-Parini I: Complement receptor 3 (CD11b/CD18) mediates type I and type II phagocytosis during nonopsonic and opsonic phagocytosis, respectively. J Immunol 169: 2003-2009, 2002.

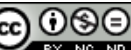

This work is licensed under a Creative Commons Attribution-NonCommercial-NoDerivatives 4.0 International (CC BY-NC-ND 4.0) License. 